\title{
Manual Sampling and Tank Size Effects on the Calibration Curve of Plot Sediment Storage Tanks
}

\author{
V. Bagarello, G. V. Di Piazza, V. Ferro
}

\begin{abstract}
In many experimental soil erosion plots, runoff is collected and carried by a conveyance system to a sequence of storage tanks. If the soil loss is measured by collecting, after mixing, samples of the stored suspension, then a calibration curve between the actual mean concentration $(C)$ and the measured concentration $\left(C_{m}\right)$ in the storage tank occurs. The aim of this article was to evaluate experimentally the factors affecting the relationship between $C$ and $C_{m}$. For a sandy loam soil, the replicated measurements of $C_{m}$ (20 samples) for two values of the actual concentration $(C=5$ and $25 \mathrm{~g} / L)$ showed that the variability of the measurements of $C_{m}$ is low and confirmed the reliability of a calibration curve obtained by a single series of runs. Results from experiments carried out with a clay soil to compare the calibration curves obtained by four field workers suggested that the maximum uncertainty in the soil loss measurement due to the choice of the calibration curve should not exceed 100\% of the true value. Moreover, the slope of the calibration curve was independent of both the water level in the tank and the field worker. Finally, a comparison among the calibration curves of a prototype tank and some model tanks was carried out for both a sandy loam and a clay soil in order to establish a scaled-up relationship among tanks of different size. Soil-specific and theoretically based scaled-up relationships were deduced.
\end{abstract}

Keywords. Calibration, Sediment concentration, Soil erosion measurement, Soil erosion plot.

$\mathrm{E}$ xperimental studies on interrill and rill erosion due to overland flow are generally carried out by soil loss measurement on plots. Runoff from a bounded plot is collected and carried by a conveyance system to a sampling unit. A simple method for measuring the sediment concentration is to store all runoff into a sequence of tanks. In each tank, stored water volume is easily determined by a water depth measurement. Sediment concentration can be measured by either catching the whole sediment amount, after siphoning the supernatant cleared water, or collecting a sample of the mixed suspension (Pierson et al., 1994). In the first case, the sediment concentration measurement is accurate, but it requires the removal of high mud volumes that have to be oven-dried. Therefore, this technique is more cumbersome and time-consuming for increasing amounts of collected runoff and number and size of plots. The sampled suspended sediment concentration is representative of the whole suspension if it is well mixed, i.e., the suspended concentration $\left(C_{i}\right)$ assumes the same value, equal to the actual concentration $(C)$ in each $i$ measurement point of the tank. Consequently, the sediment amount is calculated by multiplying the $C_{i}$ sample concentration by the runoff volume. In practice, the reliability of plot soil loss data collected by a runoff sampling technique can be questionable because the

Article was submitted for review in December 2003; approved for publication by the Soil \& Water Division of ASAE in June 2004

The authors are Vincenzo Bagarello, Associate Professor, Gian Vito Di Piazza, PhD Student, and Vito Ferro, Full Professor, Dipartimento di Ingegneria e Tecnologie Agro-Forestali, Sezione Idraulica, Università degli Studi, Palermo, Italy. Corresponding author: Vincenzo Bagarello, Dipartimento di Ingegneria e Tecnologie Agro-Forestali, Sezione Idraulica, Università degli Studi, Viale delle Scienze, 90128 Palermo, Italy; phone: +39-091-7028108, fax: +39-091-484035; e-mail: bagav@unipa. it. mixing ability of the suspended sediment influences its homogeneity within the tank, and the timing and plunging depth of the sample beaker determine the concentration of suspended sediment (Lang, 1992; Zobisch et al., 1996).

Bagarello and Ferro (1998) used both a theoretical and an experimental approach to determine the relationship (calibration curve) between the actual concentration and the measured one, obtained by collecting suspension samples from sampling taps located at different heights on the vertical of a tank wall. These authors showed that the calibration curve is linear and its slope varies with the water level in the tank. For a given soil and water level, experimental factors affecting the calibration curve include sampling direction along the vertical (up-down or down-up direction), sampling volume, suspension mixing time, and time between the end of the erosive event and the start of the sampling procedure. Therefore, a sampling procedure consistent with the one used to calibrate the sediment storage tank has to be applied in practice. For a sandy loam soil and a clay soil, previous experimental runs (Bagarello and Ferro, 1998) showed that the calibration curve is practically independent of the size distribution of the sediment entering the tank.

Several factors potentially affecting the manual sediment concentration measurement, and hence the calibration curve of a sediment storage tank, still have to be evaluated in detail.

Sediment amount stored in a tank is measured after an erosive event or a sequence of events. Generally, different workers measure the concentration of sediments stored in the tanks. Therefore, assessing the repeatability of the manual sediment concentration measurement procedure has practical importance. A preliminary investigation of the repeatability of the storage tank calibration procedure was conducted by comparing four replicated calibration curves obtained by a single worker for a sandy loam soil (Bagarello and Ferro, 1998). The calibration curves were found to be 
similar, and this suggested that the same operator repeating the same experimental procedure a given number of times should be able to determine the same calibration curve. Obviously, the repeatability of the calibration curve has to be further tested by considering a higher number of replicated experiments, conducted by different workers with different soils.

Large tanks, having a volume of approximately $1 \mathrm{~m}^{3}$, are used in the field to measure runoff from plots of a few hundred of square meters (Bagarello et al., 1996). Using these large (prototype) tanks to investigate factors affecting the calibration curve is cumbersome and time-consuming because large volumes of water and much soil have to be used for a single experiment. In practice, using small (model) tanks instead of the prototype one is desirable because less water and soil can be used. However, using a model tank instead of the prototype has practical interest if a scaled-up relationship can be established between the two tanks. A theoretically derived scaled-up relationship was proposed by Bagarello and Ferro (1998). However, this relationship has not been tested experimentally.

The general objective of this study was to evaluate experimentally factors affecting the calibration curve of sediment storage tanks for a sandy loam and a clay soil. In particular, (1) the repeatability of the manual sediment concentration measurement procedure by a single worker was tested; (2) a comparison among the calibration curves determined by different field workers was carried out; and (3) the effect of the tank size on the calibration curve was determined in order to deduce a scaled-up relationship.

\section{THEORY}

When considerable runoff events occur from a soil erosion plot, the sediment stored in a tank can be sampled by mixing the whole suspension for a given time and then by collecting one or several suspension samples. Sampling from different taps installed along a given vertical (e.g., the vertical in the middle of a tank wall) allows the operator to obtain sediment concentration values, $C_{i}\left(\mathrm{~kg} \mathrm{~m}^{-3}\right)$, at precisely known positions, i.e., the sediment concentration profile. Then, a mean concentration, $C_{m}\left(\mathrm{~kg} \mathrm{~m}^{-3}\right)$, is determined by integrating the measured sediment concentration profile. The mean measured concentration can differ from the actual concentration, $C\left(\mathrm{~kg} \mathrm{~m}^{-3}\right)$, of the suspension in the tank because the manual sampling procedure determines an incomplete mixing condition and sedimentation phenomena take place within the suspension during the sampling time (Bagarello and Ferro, 1998).

Applying the $\Pi$ theorem of dimensional analysis (Barenblatt, 1987), Bagarello and Ferro (1998) deduced theoretically the relationship between $C$ and $C_{m}$ for a tank having a square cross-section, with a side length $L(\mathrm{~m})$, containing a suspension that is sampled on a given tank wall, along its axial vertical. According to the theoretical analysis (Bagarello and Ferro, 1998), for given soil and tank water level, $h(\mathrm{~m})$, the ratio $(b)$ between the actual and the corresponding mean measured concentration is constant:

$$
C=b C_{m}
$$

Therefore, the calibration curve of the tank is linear. Bagarello and Ferro (1998) also showed that coefficient $b$ of equation 1 varies with the tank water level according to the following relationship:

$$
b=k_{1}\left(\frac{L}{h}\right)^{m_{1}}
$$

where $k_{1}$ and $m_{1}$ are numerical constants that can be estimated by two experimental runs, carried out for two different levels in a tank of known side length.

Equation 2 was used to establish a scaled-up relationship between a small model tank having a side length $L_{m}(\mathrm{~m})$ and a prototype tank having a side length $L_{p}(\mathrm{~m})$ (Bagarello and Ferro, 1998):

$$
\frac{b_{p}}{b_{m}}=\left(\frac{L_{p}}{L_{m}} \frac{h_{m}}{h_{p}}\right)^{m_{1}}
$$

where the subscripts $p$ and $m$ indicate the prototype and model tanks, respectively.

Equation 3 is based on the following assumptions:

$$
\begin{gathered}
k_{1}=k_{1 p}=k_{1 m} \\
m_{1}=m_{1 p}=m_{1 m}
\end{gathered}
$$

The $m_{1}$ constant can be determined using the model tank. The scaled-up relationship allows the experimental investigation of different factors affecting the calibration curve using a small model tank (Bagarello and Ferro, 1998).

\section{Materials AND Methods}

\section{Experimental Installation and Testing Procedure}

Six sediment storage tanks were used in the laboratory (LV1, LV2, LV3, LV4, and COL tanks) or directly in the field (FV3 tank, fig. 1) at the Sparacia experimental station for soil erosion monitoring of the University of Palermo (Bagarello et al., 1996; Bagarello and Ferro, 2004). The wooden LV1 and LV2 tanks had a volume of $0.128 \mathrm{~m}^{3}(0.47 \times 0.47 \times$ $0.58 \mathrm{~m})$ and $0.016 \mathrm{~m}^{3}(0.235 \times 0.235 \times 0.29 \mathrm{~m})$, respectively. Eight (for the LV1 tank) and five (for the LV2 tank) taps were installed along the axial vertical of a wall. In the LV1 tank, the distance between two adjacent taps was $0.10 \mathrm{~m}$ for the upper four taps and $0.05 \mathrm{~m}$ for the lower ones. A constant spacing of $0.06 \mathrm{~m}$ between taps was used in the LV2 tank. In both tanks, the lowest tap was installed at $0.02 \mathrm{~m}$ from the bottom. The LV3 and FV3 tanks were concrete and both were $0.98 \mathrm{~m}$ high. Starting from the bottom of the tank, the cross-sectional area of the LV3 tank increased from $0.80 \times$ $0.80 \mathrm{~m}^{2}$ to $0.98 \times 0.98 \mathrm{~m}^{2}$; the volume of this tank was $0.780 \mathrm{~m}^{3}$. The cross-sectional area of the FV3 tank increased from $0.99 \times 0.99 \mathrm{~m}^{2}$ to $1.01 \times 1.01 \mathrm{~m}^{2}$; the volume of this tank was $1 \mathrm{~m}^{3}$. Therefore, the linear dimensions of the LV3 and FV3 tanks were relatively similar, and they were approximately two times those of the LV1 tank and four times those of the LV2 tank. In both tanks, ten taps were installed along the axial vertical of a wall. In the LV3 tank, a constant spacing between adjacent taps, equal to $0.11 \mathrm{~m}$, was used, and the lowest tap was installed at $0.04 \mathrm{~m}$ from the bottom. In the FV3 tank, a spacing of $0.05 \mathrm{~m}$ was used for the lowest five taps, and $0.13 \mathrm{~m}$ was used for the upper five taps. The volume of the stainless steel LV4 tank was $0.160 \mathrm{~m}^{3}(0.40 \times 0.40 \times$ $1.00 \mathrm{~m})$. This tank was equipped with ten taps with a spacing 


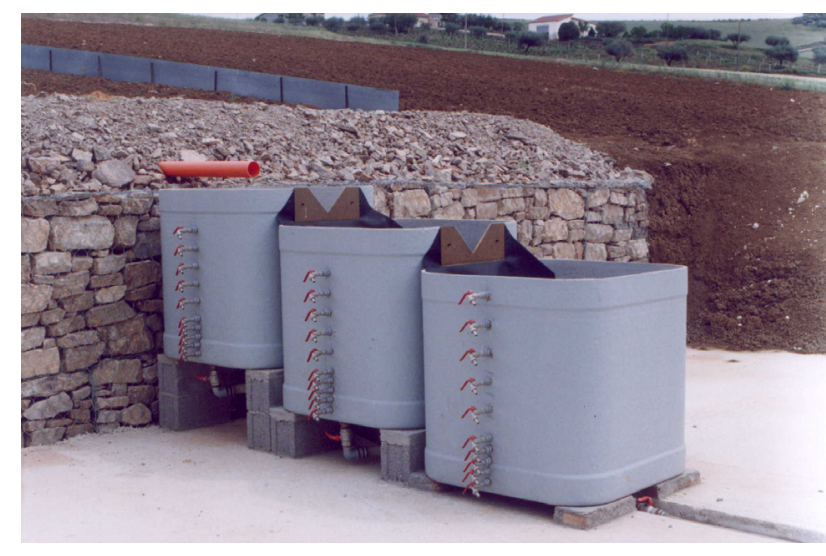

Figure 1. View of the FV3 field tanks used at the Sparacia experimental station.

of $0.10 \mathrm{~m}$, and the lowest tap was $0.03 \mathrm{~m}$ from the bottom. Finally, the cylindrical COL tank, having a volume of $0.052 \mathrm{~m}^{3}$ (diameter $=0.24 \mathrm{~m}$, height $\left.=1.15 \mathrm{~m}\right)$, was made of PVC. Ten taps were installed with a constant spacing of $0.10 \mathrm{~m}$. The distance between the lowest tap and the bottom of the tank was $0.10 \mathrm{~m}$.

A sandy loam (SL) soil taken at the Agricultural Faculty of the University of Palermo and a clay (CL) soil taken at the Sparacia experimental station were used in this investigation (fig. 2). Rock fragments and crop residuals were manually removed immediately after collecting the soil. Depending on the experiment, non-altered soil (i.e., as taken in the field) or sieved soil $(<4.76 \mathrm{~mm}$ ) was used. For most experiments, the soil was oven-dried before the experiment to use a precisely known amount of solid particles. In a few cases, the soil was air-dried before the experiment.

For a given soil, tank, and water level in the tank (and hence number of sampling taps), the mean measured sediment concentration $\left(C_{m}\right)$ corresponding to an actual sediment concentration $(C)$ was determined by first putting the soil into the tank and then by filling the tank with fresh water. The suspension was mixed manually for $5 \mathrm{~min}$ before sampling. Flat scoops, similar to the one described by Bagarello and Ferro (1998), were used to suspend the soil particles in the LV1, LV3, LV4, and FV3 tanks. The suspension was mixed by a stick in the LV2 and COL tanks. Immediately after mixing, suspension samples, each having

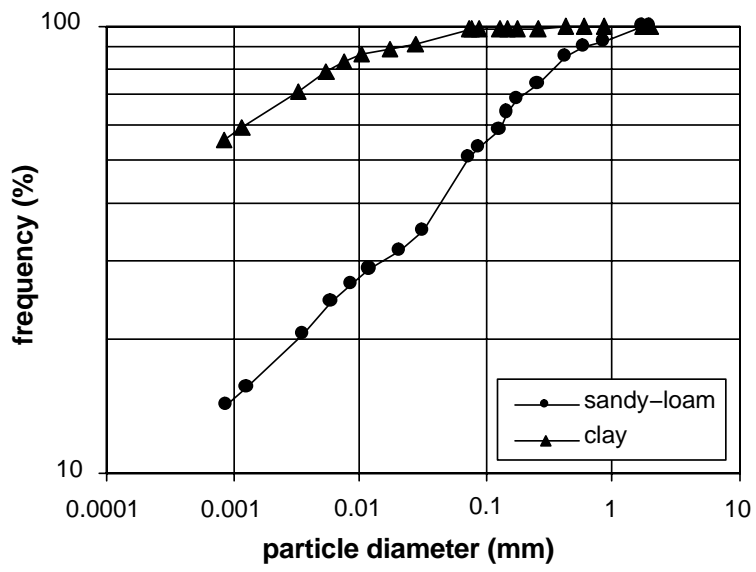

Figure 2. Particle size distribution of the investigated soils. a volume of 0.5 to $2.0 \mathrm{~L}$, depending on the tank, were taken starting from the upper tap. This up-down sampling procedure (following the sedimentation direction) was used because it produces lower gradients than the inverse procedure (Bagarello and Ferro, 1998). Each sample was oven-dried at $105^{\circ} \mathrm{C}$ for $48 \mathrm{~h}$ to obtain the local measured concentration $\left(C_{i}\right)$. The $C_{m}$ value was then calculated by integrating the measured concentration profile. According to Bagarello and Ferro (1998), a linear concentration variation between two subsequent measurement points was assumed to explain the depth-variability of the measured concentration $\left(C_{i}\right)$.

\section{Repeatability of the Sediment Concentration Measurement Procedure}

The repeatability of the sediment concentration measurement procedure was investigated for the SL soil by repeating the measurement of the mean concentration $\left(C_{m}\right) 20$ times for two values of the actual concentration $(C=5$ and $25 \mathrm{~g} / \mathrm{L})$. The experiments were conducted in both the LV1 and LV3 tanks by using soil sieved through a $4.76 \mathrm{~mm}$ sieve. Non-altered soil was also used in the LV 1 tank for $C=25 \mathrm{~g} / \mathrm{L}$. Therefore, a total of 100 measurements of $C_{m}$ were conducted. For each experiment, the water level and the sampling volume were of $0.56 \mathrm{~m}$ and $0.5 \mathrm{~L}$, respectively, in the smaller (LV1) tank and of $0.82 \mathrm{~m}$ and $1.5 \mathrm{~L}$ in the larger (LV3) one.

The CL soil was not used for this investigation because it is particularly rich in fine particles (fig. 2) that are suspended easily and tend to settle slowly. In this case, small differences in mixing effectiveness and/or sampling duration among replicated experiments are expected to have a relatively small effect as compared to the SL soil on the measured concentration.

\section{EFFECT OF THE FIELD WORKER}

Experiments were conducted with the clay soil in the FV3 tank to compare the calibration curves obtained by different workers. In particular, the calibration curves corresponding to five values of the tank water level $(h=0.13,0.22,0.43$, 0.56 , and $0.70 \mathrm{~m}$ ) were determined by four workers (WC, WD, WZ, and WV). Workers WC and WD used four values of the actual sediment concentration $(C=5,10,30$, and $60 \mathrm{~g} / \mathrm{L}$ ) for given water level, whereas workers $\mathrm{WZ}$ and $\mathrm{WV}$ used eight values of $C(C=5,10,15,30,45,60,70$, and $80 \mathrm{~g} / \mathrm{L})$. Therefore, a total of 120 measurements of $C_{m}$ were carried out. All workers operated from the tank side supporting the sampling taps. The flat scoop was introduced into the tank and a down-up movement was conducted from the bottom of the tank to the water surface (fig. 3). A different portion of the tank bottom was sampled by each scoop immersion. Non-altered soil collected at the field site and a sampling volume of 1.5 to $2.0 \mathrm{~L}$ were used. The total number of scoop movements during the mixing time was similar among workers.

The experiments conducted by workers WC and WD were used to determine a calibration curve for each value of $h$. Two calibration curves were determined by using the data collected by workers WZ and WV. In particular, the first calibration curve was obtained by using all actual concentrations $(N=8)$; the second one was determined using the same four values of $C$ used by workers WC and WD.

Only the CL soil was considered for this investigation because this soil type is available at the Sparacia experimental station, where the different workers, including students, 


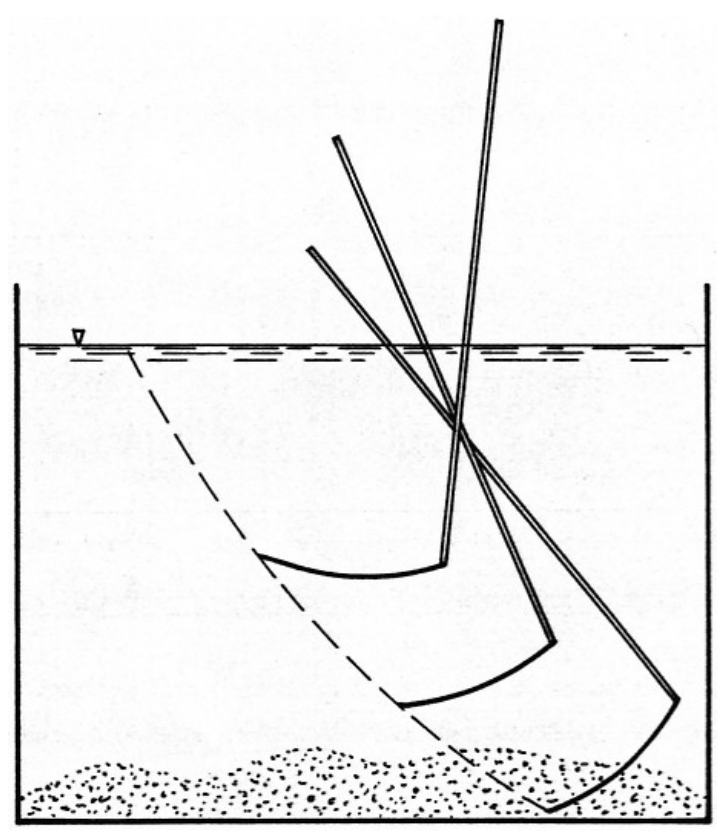

Figure 3. Mixing procedure used in the experimental runs.

contributed to measure the concentration of sediments stored in the tank.

\section{Comparison Between Model and Prototype Tanks}

An investigation was carried out with the objective of deriving experimentally a scaled-up relationship for both the SL and CL soils. In particular, the calibration curves corresponding to different water levels were determined in all the model tanks (i.e., LV1, LV2, LV4, and COL) and in the prototype tank (LV3 for the SL soil and FV3 for the CL soil). Details on the number and the minimum and maximum values of both the water levels established in each tank and the actual concentrations used to determine the calibration curve for each water level are given in table 1. Non-altered soil was used. For each experiment, the sampling volume was $0.5 \mathrm{~L}$ in the smallest tanks (LV1, LV2, LV4, COL) and 1.5 to $2.0 \mathrm{~L}$ in the largest tanks (LV3, FV3). In each tank, all possible sampling taps were used to determine $C_{m}$.

According to the theoretical analysis of Bagarello and Ferro (1998), the applicability of equation 2 was at first tested for each soil/tank combination. For the COL tank, the

Table 1. Water levels established in different tanks for the sandy loam (SL) and clay (CL) soils and actual concentrations used to determine the tank calibration curve for each water level.

\begin{tabular}{ccccccccc}
\hline & & \multicolumn{3}{c}{ Water Level } & & \multicolumn{3}{c}{ Actual Concentration } \\
\cline { 3 - 4 } Soil & Tank & $\begin{array}{c}\text { No. of } \\
\text { values }\end{array}$ & $\begin{array}{c}\text { Min. } \\
(\mathrm{m})\end{array}$ & $\begin{array}{c}\text { Max. } \\
(\mathrm{m})\end{array}$ & & $\begin{array}{c}\text { No. of } \\
\text { values }\end{array}$ & $\begin{array}{c}\text { Min. } \\
(\mathrm{g} / \mathrm{L})\end{array}$ & $\begin{array}{c}\text { Max. } \\
(\mathrm{g} / \mathrm{L})\end{array}$ \\
\hline \multirow{3}{*}{ SL } & LV1 & 6 & 0.14 & 0.49 & & 7 & 5 & 170 \\
& LV2 & 5 & 0.12 & 0.26 & & 5 & 15 & 130 \\
& LV3 & 5 & 0.16 & 0.93 & & 6 & 15 & 100 \\
& LV4 & 5 & 0.15 & 0.85 & & 6 & 15 & 100 \\
& COL & 8 & 0.32 & 1.05 & & 7 & 15 & 130 \\
\hline \multirow{6}{*}{ CL } & LV1 & 6 & 0.14 & 0.49 & & 7 & 5 & 170 \\
& LV2 & 5 & 0.12 & 0.26 & & 5 & 15 & 130 \\
& FV3 & 5 & 0.13 & 0.70 & & 4 & 5 & 60 \\
& LV4 & 5 & 0.15 & 0.85 & & 6 & 15 & 100 \\
& COL & 8 & 0.32 & 1.05 & & 7 & 15 & 130 \\
\hline
\end{tabular}

diameter $(D)$ was used in the calculations instead of the side length. For a given soil, the $b$ vs. $L / h$ relationships obtained in different tanks were then compared and a soil-specific, experimental scaled-up relationship was derived.

Note that, for the CL soil/FV3 tank combination, the experiments described in the previous section (with $b$ determined by using four actual concentrations) were used to explore the relationship between $b$ and $L / h$. Therefore, four replicated determinations of this relationship were considered, whereas a single determination of the $b$ vs. $L / h$ relationship was considered for the other soil/tank combinations. In total (i.e., including the experiments carried out with the CL soil in the FV3 tank), 416 measurements of $C_{m}$ were carried out for this investigation.

\section{RESUlts AND DiscusSiON Repeatability of the Sediment Concentration Measurement Procedure}

The ratio between the actual concentration and the mean value of the measured concentration $\left(C_{m}\right)$ varied between 2.3 and 5.2, depending on the experimental conditions, i.e., soil pretreatment, actual concentration, and tank (table 2). These results confirmed that using a storage tank as a soil loss measurement device requires calibration (Bagarello and Ferro, 1998).

The coefficient of variation $(\mathrm{CV})$ of the replicated measurements of $C_{m}$ carried out for given value of $C$ with sieved soil was similar in the two tanks, and it decreased as the actual concentration increased (table 2). Therefore, the relative variability of the $C_{m}$ measurements was more influenced by the actual concentration value than by the tank size. For all experimental conditions tested in this investigation (i.e., by considering both the non-altered soil and sieved soil pretreatments), a maximum $\mathrm{CV}$ of the $C_{m}$ data equal to 0.18 was obtained (table 2). The cumulative empirical frequency distributions of the $C_{m}$ values were nearly vertical, with a very few data points showing an appreciable deviation (fig. 4). Therefore, the variability of the individual measurements of $C_{m}$ was rather low, confirming that, generally, a calibration curve obtained by a single series of runs should adequately describe the relationship between the actual and measured concentrations (Bagarello and Ferro, 1998).

Table 2. Statistics of the mean concentration $\left(C_{m}\right)$ of soil particles measured in the LV1 and LV3 tanks by conducting 20 replicated determinations of $C_{m}$ with the SL soil for given soil pretreatment and actual concentration.

\begin{tabular}{ccccc}
\hline $\begin{array}{c}\text { Soil } \\
\text { Pretreatment }\end{array}$ & $\begin{array}{c}\text { Actual } \\
\text { Concentration } \\
(\mathrm{g} / \mathrm{L})\end{array}$ & Statistic & $\begin{array}{c}\text { LV1 } \\
\text { tank }\end{array}$ & $\begin{array}{c}\text { LV3 } \\
\text { tank }\end{array}$ \\
\hline Sieved through & 5 & Min. (g/L) & 1.54 & 1.11 \\
4.76 mm sieve & & Max. (g/L) & 2.98 & 1.84 \\
& & Mean (g/L) & 2.22 & 1.54 \\
& & CV & 0.18 & 0.15 \\
\hline Sieved through & 25 & Min. (g/L) & 7.29 & 4.01 \\
4.76 mm sieve & & Max. (g/L) & 11.28 & 5.68 \\
& & Mean (g/L) & 10.03 & 4.79 \\
& & CV & 0.10 & 0.09 \\
\hline Non-altered & 25 & Min. (g/L) & 2.89 & \\
soil & & Max. (g/L) & 8.07 & \\
& & Mean (g/L) & 6.51 & \\
& & CV & 0.18 & \\
\hline
\end{tabular}




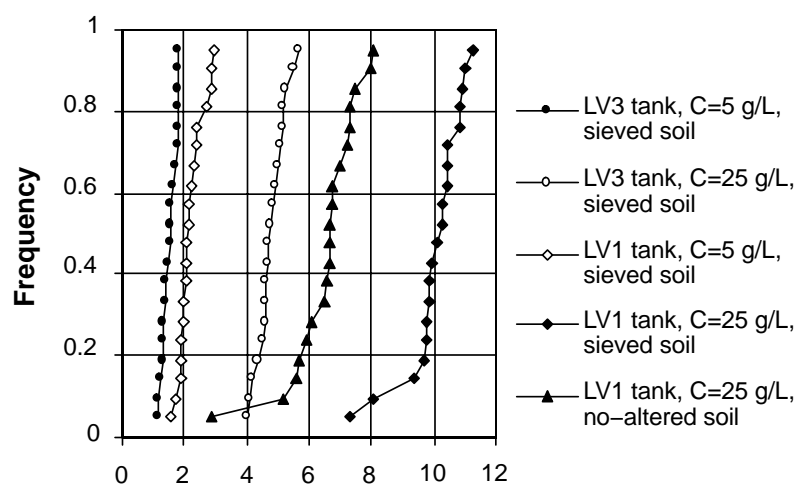

Mean measured concentration ( $g / L)$

Figure 4. Cumulative empirical frequency distribution of the mean concentrations of SL soil particles measured in the LV1 and LV3 tanks for two values of the actual concentration and different soil pretreatments.

For both actual concentrations, higher values of $C_{m}$ were obtained in the LV1 tank than in the LV3 tank (table 2), and the differences between the two tanks were statistically significant $(P=0.05)$. These results suggest that the tank used for the experiment affected the measured concentration and that a more effective mixing of the suspension was achieved in a small tank than in a large one.

Finally, lower and more variable values of $C_{m}$ were obtained with the non-altered soil than with the sieved soil (table 2), and the difference between the two soil pretreatments was statistically significant $(P=0.05)$. This result suggests that the suspension of sieved soil was more concentrated and more homogeneous than the suspension of non-altered soil. Sieving the soil mass before use probably removed the coarser particles, which cannot be sampled in practice because they have a relatively high sedimentation rate.

\section{EFFect OF THE FIELd WORKER}

Values of $b$ are listed in table 3. These values, varying by a maximum factor of approximately $2(2.58 \leq b \leq 5.89)$, were obtained for different water levels $(0.13 \leq h \leq 0.70 \mathrm{~m})$ by field workers WC, WD, WZ, and WV. Assuming that the measured values of $b$ include the true one, the maximum uncertainty in the soil loss measurement due to the choice of the calibration curve should not exceed $100 \%$ of the true value for the considered clay soil. This level of approximation occurs if the true value is $b=2.58$ and a value of $b=5.89$ is used in the calculations.

In all but one case, the linear relationship between the $\log$-transformed values of $b$ and $h$ was not statistically significant $\left(\mathrm{P}=0.05,0.03 \leq\right.$ coefficient of variation, $\mathrm{r}^{2} \leq$ 0.33 , table 3 ). The only exception was for the experiments conducted by worker WD. In this last case, $b$ decreased significantly as $h$ increased $\left(\mathrm{P}=0.05, \mathrm{r}^{2}=0.85\right)$. The slope of the calibration curve can be expected to increase with the tank water level for the following reasons: (1) the probability of obtaining well mixed suspensions decreases since larger water volumes have to be mixed, and (2) the increase of sampling duration determines a more appreciable influence of soil particle settling processes. The increase of $b$ with $h$ is expected to be more appreciable for coarse-textured soils than for fine-textured soils because the fine particles are light and are therefore suspended more easily than the coarse ones.
Table 3. Slope $(b)$ of the calibration curve determined by different workers for the clay soil, the FV3 tank, and different water levels $(h)$.

The coefficient of determination $\left(r^{2}\right)$ of the relationship between the $\log$-transformed values of $b$ and $h$ and the mean value of $b$ (i.e., $\bar{b}$ ), are also listed.

\begin{tabular}{cccccccc}
\hline & \multicolumn{7}{c}{$h(\mathrm{~m})$} \\
\cline { 2 - 6 } Worker & 0.13 & 0.22 & 0.43 & 0.56 & 0.70 & $\mathrm{r}^{2}$ & $\bar{b}$ \\
\hline WC $^{[\mathrm{a}]}$ & 3.74 & 4.62 & 4.00 & 2.58 & 3.89 & $0.15^{* *}$ & 3.77 \\
WD $^{[\mathrm{a}]}$ & 4.69 & 4.55 & 4.00 & 3.33 & 3.57 & $0.85^{*}$ & 4.03 \\
WZ $^{[\mathrm{a}]}$ & 3.95 & 4.04 & 4.41 & 5.53 & 3.45 & $0.03 * *$ & 4.28 \\
WV$^{[\mathrm{a}]}$ & 2.58 & 4.76 & 4.07 & 3.75 & 3.92 & $0.24 * *$ & 3.82 \\
WZ $^{[\mathrm{b}]}$ & 4.46 & 5.08 & 5.37 & 5.89 & 4.17 & $0.03 * *$ & 4.99 \\
WV $^{[\mathrm{b}]}$ & 3.11 & 4.28 & 3.97 & 3.66 & 4.22 & $0.33^{* *}$ & 3.85 \\
\hline
\end{tabular}

[a] Calibration curve determined by using the following actual concentrations for a given water level $(h): C=5,10,30$, and $60 \mathrm{~g} / \mathrm{L}$.

[b] Calibration curve determined by using the following actual concentrations for a given water level $(h): C=5,10,15,30,45,60,70$, and $80 \mathrm{~g} / \mathrm{L}$.

* Significantly greater than zero at the 0.05 probability level.

$* *$ Not significantly greater than zero at the 0.05 probability level.

In addition, for a fine-textured soil, the duration of the sampling procedure can be short as compared to the duration of the settling processes. However, an inverse relationship between $b$ and $h$, similar to the one obtained by Bagarello and Ferro (1998) for three soil types, can be also expected. For a given concentration, the mass of soil particles in the tank increases with the water level. Intuitively, the probability of catching soil particles with the scoop during the mixing time increases as the mass of soil particles in the tank increases. Consequently, a more concentrated suspension can be obtained as the water level in the tank increases. Therefore, the relationship between $b$ and $h$ depends on different factors having opposite effects, and for this reason it has to be deduced experimentally. For the CL soil and the FV3 tank considered in this investigation, $b$ appears to be independent of $h$, given that the relationship between these two variables was not statistically significant for most workers conducting the experiments.

The ratios between the values of $b$ deduced, for a given worker and water level, by considering different actual concentrations $(5 \leq C \leq 60 \mathrm{~g} / \mathrm{L}$ and $N=4$, or $5 \leq C \leq 80 \mathrm{~g} / \mathrm{L}$ and $N=8$ ) varied between 0.9 and 1.3 (table 3 ). In particular, data collected by worker WZ showed that increasing the number of actual concentrations determined an increase of the estimated $b$ value. However, this trend was not general since data collected by worker WV indicated that, for three water levels, $b$ decreased or remained practically constant as the number of actual concentrations increased. In general, the level of the observed discrepancies was low and probably negligible from a practical point of view.

The Tukey honestly significant difference test was applied to compare the values of $b$ obtained by the four workers (working with four values of $C$ ), notwithstanding the statistical significance of the $b(h)$ relationship determined by worker WD. No statistically significant differences were detected $(\mathrm{P}=0.05)$ among the four mean values of $b(3.77 \leq$ $\bar{b} \leq 4.28$, table 3 ), suggesting that the worker did not appreciably affect the tank calibration curve. The mean of the $b$ values obtained by different workers with different water levels was 3.97. Therefore, a value of $b=4.0$ can be suggested for practical use at the Sparacia experimental station. 
Table 4. $L / h-b$ data pairs obtained in different tanks with the sandy loam (SL) and clay (CL) soils.

\begin{tabular}{|c|c|c|c|c|c|}
\hline \multicolumn{3}{|c|}{ SL Soil } & \multicolumn{3}{|c|}{ CL Soil } \\
\hline Tank & $L / h$ & $b$ & Tank & $L / h$ & $b$ \\
\hline \multirow[t]{6}{*}{ LV1 } & 3.36 & 5.90 & LV1 & 3.36 & 3.16 \\
\hline & 2.35 & 4.73 & & 2.35 & 3.09 \\
\hline & 1.68 & 4.33 & & 1.68 & 2.31 \\
\hline & 1.31 & 3.87 & & 1.31 & 1.80 \\
\hline & 1.12 & 3.85 & & 1.12 & 1.79 \\
\hline & 0.96 & 3.80 & & 0.96 & 1.71 \\
\hline \multirow[t]{5}{*}{ LV2 } & 1.96 & 2.80 & LV2 & 1.96 & 1.34 \\
\hline & 1.47 & 2.88 & & 1.47 & 1.53 \\
\hline & 1.31 & 2.43 & & 1.31 & 1.53 \\
\hline & 0.98 & 2.69 & & 0.98 & 1.72 \\
\hline & 0.90 & 3.28 & & 0.90 & 2.35 \\
\hline \multirow[t]{5}{*}{ LV3 } & 4.92 & 10.82 & LV4 & 2.67 & 2.55 \\
\hline & 2.94 & 11.45 & & 1.14 & 3.24 \\
\hline & 2.09 & 7.11 & & 0.73 & 3.13 \\
\hline & 1.33 & 5.60 & & 0.53 & 2.53 \\
\hline & 0.86 & 5.74 & & 0.47 & 2.36 \\
\hline \multirow[t]{5}{*}{ LV4 } & 2.67 & 3.65 & $\mathrm{COL}$ & 0.75 & 1.57 \\
\hline & 1.14 & 2.34 & & 0.57 & 1.60 \\
\hline & 0.73 & 1.97 & & 0.46 & 1.44 \\
\hline & 0.53 & 2.23 & & 0.39 & 1.42 \\
\hline & 0.47 & 2.05 & & 0.33 & 1.65 \\
\hline \multirow[t]{23}{*}{ COL } & 0.75 & 2.50 & & 0.29 & 1.87 \\
\hline & 0.57 & 2.58 & & 0.26 & 2.04 \\
\hline & 0.46 & 2.72 & & 0.23 & 2.05 \\
\hline & 0.39 & 2.56 & FV3(WC) & 7.62 & 3.74 \\
\hline & 0.33 & 2.47 & & 4.50 & 4.62 \\
\hline & 0.29 & 2.54 & & 2.30 & 4.00 \\
\hline & 0.26 & 2.64 & & 1.77 & 2.58 \\
\hline & 0.23 & 3.48 & & 1.41 & 3.89 \\
\hline & & & FV3(WD) & 7.62 & 4.69 \\
\hline & & & & 4.50 & 4.55 \\
\hline & & & & 2.30 & 4.00 \\
\hline & & & & 1.77 & 3.33 \\
\hline & & & & 1.41 & 3.57 \\
\hline & & & FV3(WZ) & 7.62 & 3.95 \\
\hline & & & & 4.50 & 4.04 \\
\hline & & & & 2.30 & 4.41 \\
\hline & & & & 1.77 & 5.53 \\
\hline & & & & 1.41 & 3.45 \\
\hline & & & FV3(WV) & 7.62 & 2.58 \\
\hline & & & & 4.50 & 4.76 \\
\hline & & & & 2.30 & 4.07 \\
\hline & & & & 1.77 & 3.75 \\
\hline & & & & 1.41 & 3.92 \\
\hline
\end{tabular}

\section{Comparison Between Model and Prototype Tanks}

Table 4 lists the $(L / h, b)$ data pairs obtained in different tanks with both soils. For a given soil, the statistical significance $(\mathrm{P}=0.05)$ of the relationship between $b$ and $L / h$ (eq. 2) varied with the tank used for determining the calibration curves corresponding to different water levels (table 5). In particular, for the SL soil, a statistically significant, direct relationship between $b$ and $L / h$ was detected in the LV1, LV3, and LV4 tanks. The relationship between these two variables was not statistically significant in the LV2 and COL tanks. For the CL soil, $b$ and $L / h$ were significantly correlated by an inverse relationship in the LV2 and COL tanks and by a direct relationship in the LV1 and FV3 (worker WD) tanks. The relationship between the two
Table 5. Parameters $k_{1}$ and $m_{1}$ of equation 2 and associated coefficients of determination $\left(r^{2}\right)$ obtained in different tanks with the sandy loam (SL) and clay (CL) soils.

\begin{tabular}{ccccc}
\hline Soil & Tank & $k_{1}$ & $m_{1}$ & $\mathrm{r}^{2}$ \\
\hline SL & LV1 & 3.6754 & 0.3494 & $0.94^{*}$ \\
& LV2 & & & $0.10^{* *}$ \\
& LV3 & 5.6437 & 0.4519 & $0.81^{*}$ \\
& LV4 & 2.4745 & 0.3197 & $0.82^{*}$ \\
& COL & & & $0.27^{* *}$ \\
\hline CL & LV1 & 1.6884 & 0.5738 & $0.93^{*}$ \\
& LV2 & 1.9191 & -0.5980 & $0.77^{*}$ \\
& FV3(WC) & & & $0.15^{* *}$ \\
& FV3(WD) & 3.2429 & 0.1968 & $0.85^{*}$ \\
& FV3(WZ) & & & $0.03^{* *}$ \\
& FV3(WV) & & & $0.24^{* *}$ \\
& LV4 & & & $0.03^{* *}$ \\
& COL & 1.3151 & -0.2595 & $0.53^{*}$ \\
\hline
\end{tabular}

* $\quad$ Significantly greater than zero at the 0.05 level.

** Not significantly greater than zero at the 0.05 level.

variables was not significant in the LV4 and FV3 (workers $\mathrm{WV}, \mathrm{WZ}$, and WC) tanks.

Therefore, the dependence of the slope of the calibration curve of the prototype tank on the water level was soil-specific. In particular, the water level appreciably affected the calibration curve for the coarse-textured soil, whereas $b$ was practically independent of $h$ for the fine-textured soil. In other words, for the CL soil, $m_{1}$ must be equal to zero in order to obtain a constant $b$ value by equation 2 .

A similar trend of the relationship between $b$ and $L / h$ has to be observed in the prototype tank and in a model tank representative of the prototype one. Among the model tanks tested in this investigation, only the LV1 and LV4 tanks were potentially representative of the prototype tank for the SL soil, given that in these three tanks $b$ increased as the $L / h$ ratio increased. For the CL soil, the LV4 tank was the only tank potentially representative of the prototype one because $m_{1}$ in equation 2 can be set equal to zero for both tanks. Therefore, model tanks having cross-sectional areas much smaller than the prototype one (i.e., the LV2 and COL tanks) were not representative of the prototype tank. The representativeness of the model tanks increased as their cross-sectional areas increased. In most cases, using a model tank with a cross-sectional area equal to 0.25 times that of the prototype tank allowed similar $b(L / h)$ relationships in both tanks.

For the SL soil, the $k_{1}$ coefficient of equation 2 differed clearly among the LV1, LV3, and LV4 tanks, but the three calibration curves appeared to be nearly parallel (fig. 5). In particular, the slopes calculated for the LV1 and LV3 tanks were not significantly different $(\mathrm{P}=0.05)$, and the pooled slope was equal to 0.41 . Similarly, the slopes calculated for the LV3 and LV4 tanks were not significantly different $(\mathrm{P}=$ 0.05 ), and the pooled slope was equal to 0.38 . Therefore, a common slope among the three tanks $\left(m_{1}=0.40\right)$ appears to be usable in practice, and the following scaled-up relationship can be established between the LV1 and LV4 model tanks and the LV3 prototype tank:

$$
\frac{b_{p}}{b_{m}}=\frac{k_{1 p}}{k_{1 m}}\left(\frac{L_{p}}{L_{m}} \frac{h_{m}}{h_{p}}\right)^{m_{1}}
$$

According to equation 5, a minimum of two experimental runs have to be carried out in the prototype tank for two water 


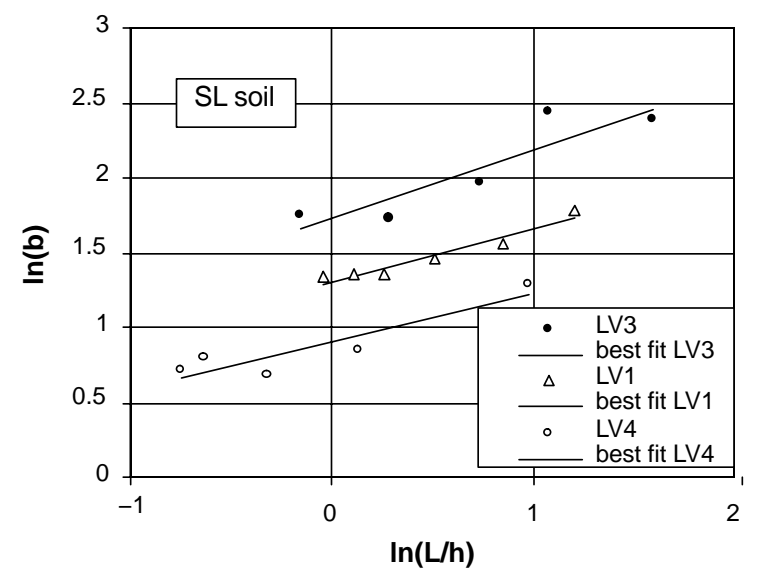

Figure 5. Relationship between the slope of the calibration curve $(b)$ and the ratio between the side length of the tank $(L)$ and the water level $(h)$ obtained with the sandy loam soil in the LV1, LV3, and LV4 tanks.

levels to determine $k_{1 p}$. The model tank can then be used to examine the influence of different factors affecting the calibration curve. The experimental procedure allows the investigator to control the independence of $m_{1}$ of the tank size, given that a few experiments have to be also conducted in the prototype tank.

For the CL soil, a scaled-up relationship can be established between the LV4 and FV3 tanks given that, for these two tanks, $b$ was found to be independent of $L / h$. The mean value of $b$ determined in the LV4 tank was equal to 2.76, whereas the mean values of $b$ obtained by different workers varied between 3.77 and 4.28 (table 3 ). The differences between the two tanks were statistically significant $(\mathrm{P}=$ 0.05), independent of the worker. Therefore, the following scaled-up relationship can be established between the LV4 and FV3 tanks:

$$
b_{p}=k_{C L} b_{m}
$$

where $k_{C L}$ varies between 1.37 and 1.55 , with a mean value of 1.44. According to equation 6, all experiments can be conducted directly in the model tank.

Both equations 5 and 6 are empirical and consistent with the theoretical analysis of Bagarello and Ferro (1998). For both the SL and CL soils, an additional term $\left(k_{1 p} / k_{1 m}\right.$ or $\left.k_{C L}\right)$ has to be included in equation 3. For the CL soil, $m_{1}$ has to be set equal to zero.

\section{Conclusions}

The general objective of this study was to evaluate factors affecting the measured sediment concentration and hence the calibration curve of sediment storage tanks for a sandy loam and a clay soil.

Sediment amount stored in a tank has to be measured after each erosive event, but little information is available on the variability of repeated sediment concentration measurements. The repeatability of the measurement procedure by a single worker was evaluated in two tanks of different size for the sandy loam soil. For this soil, the mean measured concentration $\left(C_{m}\right)$ was expected to be particularly susceptible to small differences in the sampling procedure due to the large amount of relatively coarse soil particles, which are difficult to sample. The study confirmed that using a storage tank as a soil loss measurement device requires calibration, given that the actual concentrations $(C)$ were 2.3 to 5.2 times larger than the mean measured ones. The relative variability of $C_{m}$ increased as the actual concentration decreased. However, this variability was rather low $(\mathrm{CV} \leq 0.18)$ for all the tested soil pretreatments, actual concentrations, and tanks. The tank used for the experiment affected the measured concentration, and a more effective mixing of the suspension was achieved in the smaller tank. It was concluded that, generally, a calibration curve obtained from a single series of runs should adequately describe the relationship between the actual and the measured concentration.

Various workers, including students, generally measure the concentration of sediments stored in tanks. Therefore, assessing the sensitivity of the measured concentrations to the field worker has practical importance. An investigation was conducted with the clay soil in the field tank used at the Sparacia experimental station to compare the calibration curves obtained by four field workers for different water levels $(h)$ in the tank. The maximum uncertainty in the soil loss estimation attributable to the choice of the calibration curve was found to be equal to $100 \%$ of the true value. In general, the slope $(b)$ of the calibration curve relating $C$ to $C_{m}$ did not vary significantly with $h$, and no statistically significant differences were detected among the mean values of $b$ obtained by different workers $(3.77 \leq \bar{b} \leq 4.28)$. It was concluded that the worker did not appreciably affect the tank calibration curve for the considered clay soil. A value of $b=$ 4.0 was suggested for practical use at the Sparacia experimental station.

Using a model tank instead of the prototype tank to investigate factors affecting the calibration curve of the tank has practical interest if a scaled-up relationship can be established between the two tanks. An investigation was carried out with the objective of deriving experimentally a scaled-up relationship for both the SL and CL soils. In particular, the calibration curves corresponding to different water levels were determined in four model tanks having different side lengths $(L)$ and in the prototype tank. The relationship between $b$ and $L / h$ determined on the prototype tank depended on the soil type. In particular, the water level affected appreciably the calibration curve for the coarse-textured soil, whereas $b$ was practically independent of $L / h$ for the fine-textured soil. Model tanks having cross-sectional areas much smaller than the prototype were not representative of the prototype tank, independent of the soil type. The representativeness of the model tanks increased as their cross-sectional areas increased. In most cases, using a model tank with a cross-sectional area equal to 0.25 times that of the prototype tank revealed similar $b(L / h)$ relationships in both tanks. Soil-specific, scaled-up relationships were derived. These relationships showed similarities with a scaled-up relationship deduced in the past by a purely theoretical approach. However, determining a scaled-up relationship needs further work given that a few inconsistent results were obtained for the CL soil. They include the sign of the $m_{1}$ coefficient (positive, negative, equal to zero) of the $b(L / h)$ relationship determined in the prototype tank, which was not consistent among all workers, and the different behavior of the LV1 and LV4 tanks, which have similar cross-sectional areas. With the exception of the prototype tank/CL soil combination, a single set of $(b, h)$ data was considered for 
each tank/soil combination. A higher number of replicated data sets for each tested tank is advisable to test the proposed conclusions.

\section{ACKNOWLEDGEMENTS}

This research is supported by the grant PIC INTERREG III B - MEDOCC - Progetto "DESERTNET". G. V. Di Piazza developed this research for his $\mathrm{PhD}$ activity, which is co-funded by the European Social Fund of the European Community. All authors set up the research, analyzed the results, and participated in writing the article.

\section{REFERENCES}

Bagarello, V., and V. Ferro. 1998. Calibrating storage tanks for soil erosion measurement from plots. Earth Surface Processes and Landforms 23(13): 1151-1170.

Bagarello, V., and V. Ferro. 2004. Plot-scale measurement of soil erosion at the experimental area of Sparacia (southern Italy). Hydrological Processes 18(1): 141-157.
Bagarello, V., V. Ferro, G. Giordano, and M. Minacapilli. 1996. Indagini sperimentali sui deflussi e sull'erosione idrica nei piccoli bacini. In Proc. Regional Workshop:" POP Sicilia Cartografia Tematica, Morfologia delle Coste, Erosione del Suolo e Gestione dei Sedimenti," 51-62. J. Mègier, S. Falving, and M. L. Paracchini, eds. Palermo, Italy: Space Applications Institute, Environmental Mapping and Modelling Unit, Centro Comune di Ricerca di ISPRA della Commissione Europea.

Barenblatt, G. I. 1987. Dimensional Analysis. Amsterdam, The Netherlands: Gordon and Breach.

Lang, R. D. 1992. Accuracy of two sampling methods used to estimate sediment concentration in runoff from soil-loss plots. Earth Surface Processes and Landforms 17(8): 841-844.

Pierson, F. B., Jr., S. S. Van Vactor, W. H. Blacburn, and J. C. Wood. 1994. Incorporating small-scale spatial variability into predictions of hydrologic response on sagebrush rangelands. In Variability of Rangeland Water Erosion Processes, 23-34. SSSA Special Publication 38. Madison, Wisc.: SSSA.

Zobisch, M. A., P. Klingspor, and R. A. Oduor. 1996. The accuracy of manual runoff and sediment sampling from erosion plots. $J$. Soil and Water Conservation 51(3): 231-233. 